DEMOGRAPHIC RESEARCH

VOLUME 35, ARTICLE 41, PAGES 1213-1244

PUBLISHED 26 OCTOBER 2016

http://www.demographic-research.org/Volumes/Vol35/41/

DOI: 10.4054/DemRes.2016.35.41

Research Article

\title{
Who brings home the bacon? The influence of context on partners' contributions to the household income
}

\section{Agnese Vitali \\ Bruno Arpino}

This publication is part of the Special Collection on "Finding Work-Life Balance: History, Determinants, and Consequences of New Bread-Winning Models in the Industrialized World," organized by Guest Editors Trude Lappegård, Fran Goldscheider, and Eva Bernhardt.

\section{(C)2016 Agnese Vitali \& Bruno Arpino.}

This open-access work is published under the terms of the Creative Commons Attribution NonCommercial License 2.0 Germany, which permits use, reproduction \& distribution in any medium for non-commercial purposes, provided the original author(s) and source are given credit. See http:// creativecommons.org/licenses/by-nc/2.0/de/ 


\section{Contents}

1 Introduction 1214

$2 \quad$ Background and hypotheses 1215

2.1 Characteristics of female-breadwinner couples 1215

2.2 The role of attitudes towards gender equality 1216

$\begin{array}{lll}2.3 & \text { The role of male unemployment } & 1217\end{array}$

$3 \quad$ Data and method 1219

$\begin{array}{lll}3.1 & 1219\end{array}$

$\begin{array}{ll}3.2 & \text { Variables used in the regression model } \\ 3.3219\end{array}$

3.3 The multinomial multilevel model 1223

$4 \quad$ Results 1224

4.1 Regression results 1224

$4.2 \quad$ Predicted probabilities 1226

$\begin{array}{lll}\text { 4.2.1 The contextual correlates of male-breadwinner couples } & 1227\end{array}$

$\begin{array}{ll}\text { 4.2.2 The contextual correlates of female-breadwinner couples } & 1229\end{array}$

4.2.3 The contextual correlates of equal-income couples 1232

5 Conclusions 1235

$\begin{array}{lll}6 & 1237\end{array}$

$\begin{array}{ll}\text { References } & 1239\end{array}$

$\begin{array}{ll}\text { Appendix } & 1244\end{array}$ 


\title{
Who brings home the bacon? The influence of context on partners' contributions to the household income
}

\author{
Agnese Vitali ${ }^{1}$ \\ Bruno Arpino ${ }^{2}$
}

\begin{abstract}

\section{BACKGROUND}

Female-breadwinner families represent a relatively new phenomenon in Europe. Little is known about the determinants of this couple type, which sensibly diverts from the traditional economic superiority of men within the household.
\end{abstract}

\section{OBJECTIVE}

This paper studies the contextual correlates of partners' contribution to the household income, distinguishing between female-breadwinner, male-breadwinner, and equalincome couples. In particular, it focuses on the role of male unemployment rate and the prevalence of gender-egalitarian attitudes as possible explanations for the emergence of female-breadwinner and equal-income couples across European regions and countries.

\section{METHOD}

Using data from the fifth round (2010/2011) of the European Social Survey, integrated with data from the Eurostat database, we model the categorical variable identifying the couple type (male-breadwinner, female-breadwinner, or equal-income couple) by using a multilevel multinomial logistic regression model where individuals are nested within regions and countries.

\section{RESULTS}

The prevalence of female-breadwinner, male-breadwinner, and equal-income couples varies considerably across European countries as well as within countries. The prevalence of female-breadwinner couples is positively associated with male unemployment, while it is not influenced by the diffusion of gender-egalitarian attitudes. However, the diffusion of gender-egalitarian attitudes matters for explaining the variation in the prevalence of equal-income couples across Europe.

\footnotetext{
${ }^{1}$ University of Southampton and ESRC Centre for Population Change, UK. E-Mail: a.vitali@soton.ac.uk.

${ }^{2}$ Universitat Pompeu Fabra, Spain.
} 
Vitali \& Arpino: The influence of context on partners' contributions to the household income

\section{CONTRIBUTION}

We add to the literature on partners' contributions to household income by analysing the spatial distribution and the contextual correlates of female-breadwinner, malebreadwinner, and equal-income couples across European countries and regions.

\section{Introduction}

In the context of the declining male-breadwinner-female-homemaker-model of the family and the increasing number of dual-income couples, breadwinning women represent a significant proportion of couples in the developed world today (Winkler, McBride, and Andrews 2005; Wang, Parker, and Taylor 2013; Wooden and Hahn 2014; Vitali and Mendola 2014; Klesment and Van Bavel 2015). ${ }^{3}$

Yet, despite the increasing prevalence of female-breadwinner couples, and despite the fact that this couple type significantly diverges from the traditional malebreadwinner model which has characterized families in the developed world for most of the 20th century (Becker 1981; Esping-Andersen 2009; Ruggles 2015), little is known about its determinants.

In this paper we contribute to filling a gap in the literature, by studying the contextual correlates of partners' contributions to the household income, with particular emphasis on female-breadwinner couples. Specifically, we study the probability of belonging to a female-breadwinner couple, i.e., a couple where the woman is the sole or the main income provider, in comparison to two other couple types: the traditional male-breadwinner model, i.e., couples where the man is the sole or the main income provider, and equal-income couples, i.e., couples where both partners provide roughly an equal share of the household income. We focus on the influence of the context of region of residence in explaining observed cross-country and within-country differences in the prevalence of female-breadwinner, male-breadwinner, and equal-income couples in Europe.

We develop and test two main hypotheses regarding the contextual drivers of the prevalence of female-breadwinner couples. Inspired by scholars who have used both cultural and structural interpretations to explain family change (e.g., Lesthaeghe and Neidert 2006; Esping-Andersen 2009; Gerson 2010; Cherlin 2016), we study the

\footnotetext{
${ }^{3}$ For simplicity, we will use the term 'female-breadwinner couples' to identify families where the woman is the sole income provider as well as those where both partners are income providers but the woman contributes the largest share of their household income. We acknowledge that the 'pure' female-breadwinner model evokes a specialization of gender roles opposite to that observed in the Beckerian family model, i.e., with the woman as the sole income provider (Warren 2007).
} 
emergence of female-breadwinner couples as a by-product of the spread of new genderegalitarian attitudes in combination with economic structural or institutional barriers which hamper men's employment and earnings.

Our approach follows Drago, Black, and Wooden (2005), who first theorized the existence of the two heterogeneous drivers of female-breadwinner families, i.e., economic reasons and genuine choice driven by an ideology of gender equality, and identified such a typology for Australia. The first contribution of this paper is to provide an empirical test of the hypotheses developed in Drago, Black, and Wooden (2005) using a regression approach applied to micro-level data from the European Social Survey for 24 European countries plus Russia and Israel, referring to the years 2010/2011. The second contribution of the paper is to document the existence of subnational differences in the way in which partners contribute to household income across Europe.

Our results show that male unemployment rate significantly correlates with the probability of observing female-breadwinner families. Hence we find support for the hypothesis that economic necessity is an important driver of the economic supremacy of women over men, at least during a period of economic recession such as 2010/2011. Gender-egalitarian attitudes, however, do not show any statistically significant association with the probability of observing female-breadwinner families. On the other hand, gender-egalitarian attitudes are positively and significantly associated with the probability of observing equal-income families. The prevalence of male-breadwinner families is associated with both low male unemployment rate and low genderegalitarian attitudes.

\section{Background and hypotheses}

\subsection{Characteristics of female-breadwinner couples}

Existing studies have described the sociodemographic characteristics of femalebreadwinner couples. These studies find that the woman's contribution to the household income is associated with her education and labour force participation (Raley, Mattingly, and Bianchi 2006), with the educational differentials (Vitali and Mendola 2014; Klesment and Van Bavel 2015) and age differentials between partners (Bloemen and Stancanelli 2013), and family size (Bianchi, Casper, and Peltola 1999). Previous studies have shown that female-breadwinner couples can represent a permanent or a temporary arrangement (Winkler, McBride, and Andrews 2005). Temporary femalebreadwinner couples have considerably less net household worth than malebreadwinner couples, while permanent female-breadwinner couples have more (Drago, 
Black, and Wooden 2005). In a study of female breadwinners in Australia, Drago, Black, and Wooden (2005) theorize that female-breadwinner couples do not represent a homogeneous group of women and men. Drago and colleagues identify a typology of female-breadwinner couples which distinguishes whether becoming a female breadwinner is the result of economic necessity, driven by the man's unemployment or underemployment status, or whether it is a genuine choice, driven by the woman's career ambitions and her higher earning potential with respect to the male partner.

\subsection{The role of attitudes towards gender equality}

The diffusion of female-breadwinner (and equal-income) couples can be thought of as part of a gradual process of the diffusion of new ideas and behaviours of gender equality that have spread across people and places, eroding the superiority of men as income providers for their families. Historically, women were employed in paid work for economic necessity, and it is not until the 1970s that women started to pursue careers in the labour market (Hakim 2000; Goldin 2006).

The difference between female-breadwinner and dual-income couples is that in the former the woman's contribution to the household income is central, whereas in the latter case it can be equal, secondary, or marginal compared to the man's share (Oppenheimer 1994; Esping-Andersen 2009; Blossfeld and Drobnic 2001).

If the woman has higher income potential than the man, we might envisage that female-breadwinner couples exist as the result of a utility-maximization process that justifies the specialization of gender roles. The female-breadwinner couple sensibly diverges from the normative male-breadwinner model of the family and hence it can only be conceived in contexts characterized by gender-egalitarian attitudes in the private sphere of the family (McDonald 2013). 'Gender flexibility' in sharing breadwinning and caring responsibility (Gerson 2010) can be thought of as a precondition for this deviation from the traditional arrangement to become acceptable.

Previous research has demonstrated the existence of a link between couples' income arrangement and gender-egalitarian attitudes at the individual and contextual levels. Baxter and Kane (1995) show that women's economic dependency is associated with less gender-egalitarian attitudes. Cha and Thébaud (2009) show that men in female-breadwinner (and equal-income) couples tend to be more gender-egalitarian than men in other couple types. The role of gender-egalitarian attitudes has also been studied with regard to a series of outcomes related to couples' relative incomes. One example is the couples' division of housework. A general result in the literature is that the man's housework hours increase with the woman's contribution to the household income, while the woman's housework hours decline (Bianchi et al. 2000). Despite this 
result, breadwinning women are found to contribute more housework than men (Tichenor 2005; Schneider 2011; Aassve, Fuochi, and Mencarini 2014). The institutional context is an important moderator of the association between housework and personal contribution to household income (Breen and Cooke 2005). Egalitarian societies, such as the Nordic countries and France, facilitate outsourcing of family activities such as childcare and care for the elderly, while these tasks are a prerogative of women in settings characterized by low gender equality in the private sphere, such as the Southern European countries (McDonald 2013; Esping-Andersen and Billari 2015). Another example is the risk of union dissolution, which is higher for femalebreadwinner couples than for other couple types in contexts where the traditional gendered division of labour is reinforced by institutional arrangements (Cooke 2006), such as in Germany. On the contrary, in the US (Schwartz and Han 2014) and in more gender-egalitarian societies such as Denmark (Esping-Andersen and Holm 2014), the risk of union dissolution is not influenced by the woman's economic advantage.

Hence, we may envisage that the diffusion of female-breadwinner (and equalincome) couples is the product of the diffusion of gender-egalitarian attitudes. Therefore our first hypothesis is that the prevalence of female-breadwinner and equalincome couples will be higher in those contexts which are closer to completing the gender revolution in the two-part framework developed by Goldscheider, Bernhardt, and Lappegård (2015), or reaching the Pareto-optimal equilibrium of the gender egalitarian family model in Esping-Andersen and Billari's (2015) multiple equilibria framework. We expect that male-breadwinner couples will be low in those areas where gender-egalitarian attitudes are more widespread.

\subsection{The role of male unemployment}

Equally plausibly, we may envisage that the observed prevalence of femalebreadwinner (and equal-income) couples is the result of structural barriers that constrain women's and men's preferences concerning their labour market participation and earning potential.

From the 1970s the rate of enrolment of women in higher education and female labour force participation started to increase substantially, at the same time as men's salaries and job prospects started to deteriorate, especially among the lower-educated (Wilson 1987; Oppenheimer 1994; Bernhardt, Morris, and Handcock 1995; Blossfeld et al. 2006). Sironi and Furstenberg (2012) show that the share of young American men who were able to support a family in the 2010s was considerably lower than in the 1970s. As a result of globalization, modernization, and underlying changes in the labour market, women's labour force participation and earnings have increased relative to 
men's (Goldin 2006; Esping-Andersen 2009; Ruggles 2015). Also, among the younger cohorts, women have outpaced men in higher education (Van Bavel 2012). We may therefore envisage that the existence of female-breadwinner couples is linked to the relative economic advantage of women compared to their partners.

We focus on male unemployment rate as a measure of difficult labour market circumstances for men. The role of male unemployment as a driver of changing patterns of couples' relative incomes is particularly timely, given that during the 2008 economic crisis many European countries witnessed declining real earnings and increased unemployment rates particularly for men. The explanation for this trend is that men, on average, suffered from higher unemployment and underemployment more than women due to the gender distribution across different industries that were unevenly affected by the business cycle (Hoyne, Miller, and Schaller 2012; Cho and Newhouse 2012; Harkness 2013). The number of female-breadwinner families increased during the 2008 economic crisis, especially in those countries particularly hard hit by the recession such as Greece and Spain (Vitali and Mendola 2014; Klesment and Van Bavel 2015; Cory and Stirling 2015). Some authors have argued that the increase in the prevalence of female-breadwinner couples is directly linked to the rise in male unemployment (Smith 2009; Harkness and Evans 2011; Bettio et al. 2012).

Therefore, our second hypothesis is that female-breadwinner families will be more prevalent in those regions where male unemployment rates are higher. For malebreadwinner families we expect the opposite relation to hold.

Regarding the correlation between male unemployment and the likelihood of observing equal-income families, we expect two opposing mechanisms to be at play. On the one hand, high unemployment for men may decrease the likelihood of equalincome couples in favour of female breadwinners, because an increased number of men lose their jobs and hence stop contributing to the household income, making women the sole or main income provider for their families. On the other hand, increased unemployment in the male-dominated sectors may imply increased economic uncertainty in such sectors. Hence, those men who remain employed may face lower wages than before the economic crisis, leading to a decrease in their contribution to the household income. Men who used to be the main income provider for their families may now contribute less to their household income and may reach the point where their contribution equals that of the woman. In that case, high unemployment for men may decrease the likelihood of male-breadwinner couples in favour of equal-income couples. 


\section{Data and method}

\subsection{European Social Survey}

We use data from the fifth round of the European Social Survey (ESS-5) ${ }^{4}$ collected in 2010/2011. ESS-5 contains a question on the respondent's relative contribution to the household income, which allows identifying the main income provider within a couple. This question was asked also in ESS-2 (2004/2005); however, earlier ESS surveys did not allow for the identification of NUTS regions, which are crucial for the analyses carried out in the present study.

The ESS is representative of European populations aged 15 or older. We restricted our sample to individuals who are currently coresiding with a heterosexual spouse or partner (with or without children), with both partners aged between 25 and 54 years (prime earning age), and with none of the partners being disabled, in education, military service, retired, or 'other'. ESS is not a household survey, but respondents who are in a partnership are asked to provide information on their partner's main characteristics. For this reason, the sample includes both female and male respondents and the couple is considered the unit of analysis.

The final sample is constituted of 12,822 respondents, nested into 192 regions and 26 countries. In order to identify regions we refer to the NUTS2 statistical classification, with a few exceptions. For Germany and the UK, for which the information on NUTS2 is not available in the ESS, we refer to the NUTS1 statistical classification. Cyprus and Israel do not have NUTS: hence they are treated as a single region. For three countries, Russia, Ukraine, and Estonia, although information on the NUTS2 or other regional classifications is available in the ESS, the information on regional male unemployment is not available. As a result, these countries are treated as a single region. ${ }^{5}$

\subsection{Variables used in the regression model}

As the dependent variable we use the nominal variable indicating whether each respondent belongs to a male breadwinner, female-breadwinner, or equal-income couple, based on a self-reported measure of their contribution to the household income ("Around how large a portion of the household income do you provide yourself?"). We define the couple as male-breadwinner when the female (male) respondent answered

\footnotetext{
${ }^{4}$ Data and documentation can be freely downloaded from http://www.europeansocialsurvey.org.

${ }^{5}$ We have considered a different model specification where individuals are clustered within NUTS-1 rather than NUTS-2 regions. Results from this model (not shown) are very similar to those presented here.
} 
Vitali \& Arpino: The influence of context on partners' contributions to the household income

"none", "very small" or "under a half" ("over a half", "very large", or "all"); as femalebreadwinner when the female (male) respondent answered "over a half", "very large" or "all" ("none", "very small" or "under a half"); and as equal-income when the respondent answered "about half".

Our choice of explanatory variables follows the discussion presented in the background section. The main explanatory variables of interest are those measuring the contextual influences of male unemployment rate and gender-egalitarian attitudes in the region of residence. We use the regional male unemployment rate (for ages 25 and above) gathered from the Eurostat Regional Database and, when not available in this database (for Israel, Russia, and Ukraine), from the Database of Labour Statistics of the International Labour Organization. ${ }^{6}$ Following Arpino and Tavares (2013) and Arpino, Esping-Andersen, and Pessin (2015), we construct an indicator of gender equality from the ESS survey question that states, "When jobs are scarce, men should have more right to a job than women". The question offers five possible answers, from "agree strongly" to "disagree strongly". We dichotomize this variable to take value 1 if the answer is "disagree" or "disagree strongly" and 0 otherwise. The gender equality indicator is constructed by averaging the dichotomous individual variable by region. When computing the regional average, we consider respondents of any age. As an alternative, we considered averaging the original 5-point variable. The results (not shown) were qualitatively similar to those presented here.

The regression model also includes a set of individual-level control variables: gender of respondent (male=ref.), age of respondent (linear and quadratic term), woman's educational attainment (low=ref.; medium; high), education differential between partners (women achieved lower education level=ref.; partners achieved same education level; woman achieved higher education level), number of children in the household, couple resides in urban area (rural=ref.). The number of children in the household may be endogenous with respect to our outcome variable. As suggested by Aassve, Arpino and Billari (2013), when the interest lies in assessing the effect of contextual variables one should avoid controlling for variables that are themselves likely to be affected by the context. Therefore, as a robustness check, we also ran the models without controlling for number of children. Since the results were very similar to those obtained when including this variable, we opted for showing estimates of the full model. The choice of individual-level variables is based on previous studies, which have demonstrated that male respondents tend to underreport earning less than their female partners, and that female breadwinners are likely to be childless, highly educated, and more educated than their partners (see, e.g., Raley, Mattingly, and

\footnotetext{
${ }^{6}$ The ESS survey was carried out between 2010 and 2011 (2011 and 2012 in Ireland). For each country, we assign the male unemployment rate measured in the year when the majority of respondents participated in the ESS survey. Data for Israel and Russia refer to the total male unemployment rate for all ages.
} 
Bianchi 2006 and Vitali and Mendola 2014 and the literature cited therein). We also control for age of respondent and for whether the couple resides in an urban/rural area, to account for the fact that female-breadwinner couples, as a 'new' family type, are likely to originate and spread among the younger age groups of the population and in urban settings (Vitali, Aassve, and Lappegård 2015). Finally, we also included female labour force participation at the regional level as a control variable.

Figures 1 and 2, respectively, show the values of the male unemployment rate and the gender equality index across the ESS regions. While some countries are characterised by a homogenous level of male unemployment (e.g., homogeneously high in Spain and Ireland, homogeneously low in Norway), other countries are characterized by regional variability in male unemployment (e.g., France). The male unemployment rate ranges between $2 \%$ in the Dutch region of Zeeland, the Swiss region of Zentralschweiz, and the Norwegian region of Agder and Rogaland, to above $25 \%$ in the Spanish regions of Andalucía and Canarias. The map in Figure 1 reflects the fact that the economies of the Southern and Eastern European countries and Ireland were especially hard hit by the 2008 economic crisis.

Similarly, a regional pattern is also observed in the prevalence of genderegalitarian attitudes. The Scandinavian countries homogeneously show the highest values of the gender equality index (above 84\%), together with some regions of the Netherlands and Belgium. The highest value of the gender equality index in the sample is equal to $100 \%$ and is found in the Swedish region of Norrbottens län, the Danish region of Sjæland, the French regions of Picardie and Limousin, the Dutch regions of Groningen and Drenthe, the German province of Bremen, and the Spanish region of Comunidad Foral de Navarra. Southern and Eastern European countries (with the exception of Spain) homogeneously show low and medium-low values (below $70 \%$ ). The lowest values of the gender equality index in the sample are found in the Spanish region of Ciudad Autónoma de Melilla (0\%), in the Greek region of Sterea Ellada, and in the Hungarian region of Borsod-Abauj-Zemplen (both 13\%). Spain, France, Belgium, Germany, and the Netherlands show a considerable degree of within-country heterogeneity in gender equality. ${ }^{7}$

\footnotetext{
${ }^{7}$ The gender equality index in France ranges between a low of $40 \%$ in the province of Bourgogne to a high of $100 \%$ in the provinces of Picardie and Limousin; in Spain between $0 \%$ in the Ciudad Autónoma de Melilla to $100 \%$ in the Comunidad Foral de Navarra; in Germany between 57\% in Hamburg and 100\% in Bremen; in the Netherlands from $60 \%$ in Zeeland to $100 \%$ in Groningen and Drenthe.
} 
Vitali \& Arpino: The influence of context on partners' contributions to the household income

\section{Figure 1: Regional male unemployment rate (2010-2011), quartiles}

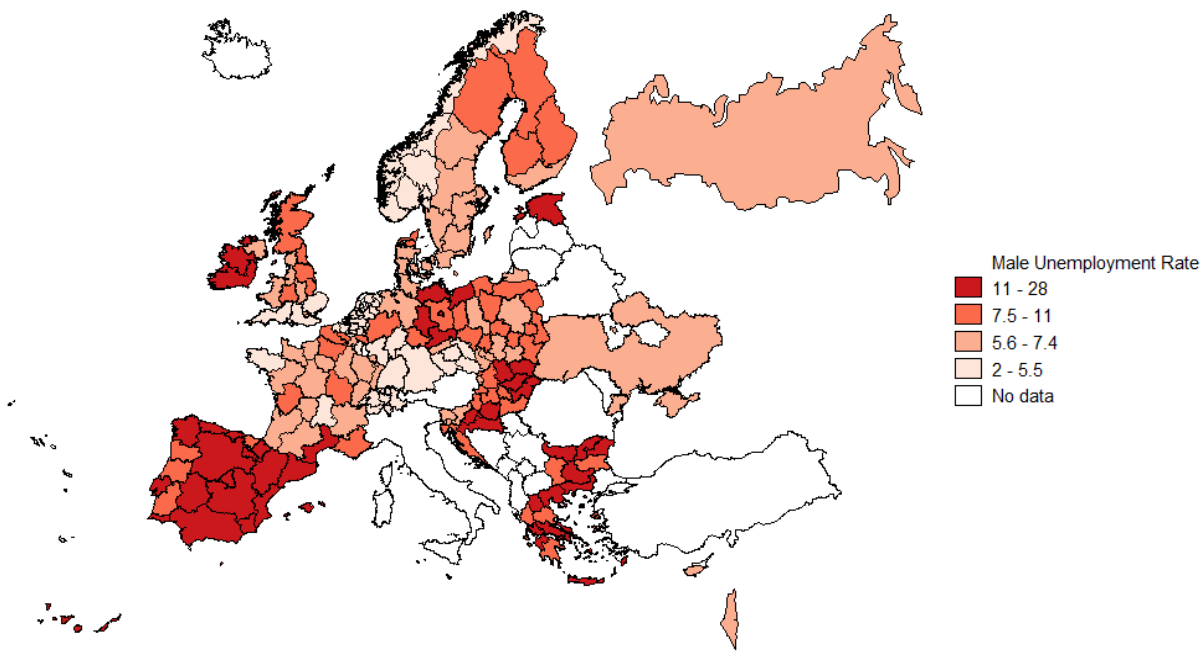

Note: Regional male unemployment rate refers to males aged 25 and above (total male unemployment for Israel and Russia). Data source: Eurostat Regional Database (Database of Labour Statistics of the International Labour Organization for Israel, Russia, and Ukraine). The male unemployment rate refers to the year when all or the majority of ESS respondents were surveyed. It refers to 2010 for Germany, UK, Estonia, Switzerland, Denmark, Finland, France, Hungary, Netherlands, Norway, Poland, Sweden, Slovenia, and Slovakia. It refers to 2011 for the remaining countries. 
Figure 2: Regional gender equality index, quartiles

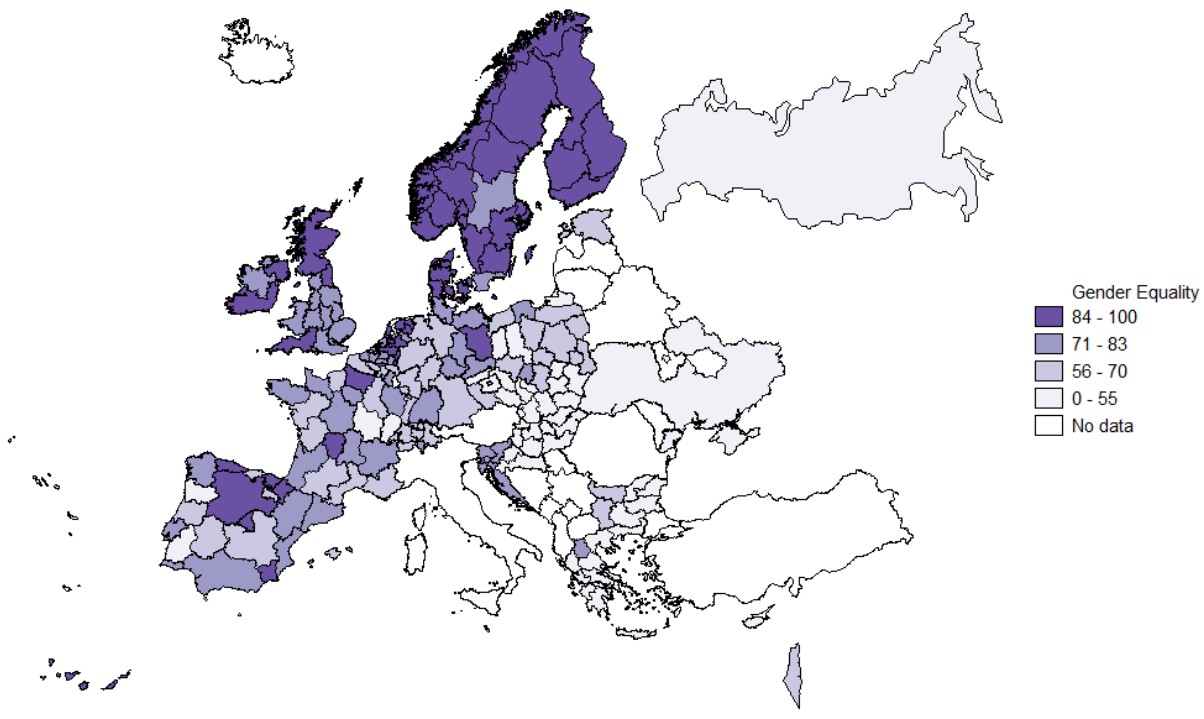

Note: The regional gender equality index measures the regional percentage of ESS respondents of any age agreeing or strongly agreeing with the statement "when jobs are scarce, men should have more right to a job than women".

\subsection{The multinomial multilevel model}

The nominal nature of our dependent variable, i.e., the couple type, calls for using a multinomial regression model. Our dataset is characterised by a hierarchical structure with individuals nested into regions and countries. Therefore, a multilevel multinomial regression model is needed to take into account the fact that observations are not independent within regions and countries. We estimate a 3-level model with random effects at the regional and country levels. This modelling approach allows us to highlight the existing spatial heterogeneity in the prevalence of female-breadwinner couples and equal-income couples as opposed to male-breadwinner couples (ref.) across and within European countries. Also, this modelling approach allows assessing to what extent the prevalence of the three different couple types is associated with gender equality and/or male unemployment. 


\section{Results}

\subsection{Regression results}

Table 1 reports the estimates from the three-level multinomial logistic regression model. The estimates reported in the two columns refer, respectively, to the effects of being in a female-breadwinner and in an equal-income couple as compared to a malebreadwinner couple.

The sign and significance of the individual-level variables are in line with previous findings (see, e.g., Raley, Mattingly, and Bianchi 2006; Bloemen and Stancanelli 2013; Vitali and Mendola 2014; Klesment and Van Bavel 2015). On average, male respondents are less likely than female respondents to report being in an equal-income or female-breadwinner couple (as opposed to a male-breadwinner couple). The probability of being in an equal-income or female-breadwinner couple increases with age and decreases with the number of children. Both equal-income and femalebreadwinner couple types are more likely than the male-breadwinner arrangement when the woman is older and when she is equally or more educated than her partner. The probability of being in an equal-income couple rather than a male-breadwinner couple increases with the woman's educational attainment. There is a U-shape relationship between the woman's education and the probability of belonging to a femalebreadwinner couple: both high-educated and low-educated women show a higher probability of belonging to a female-breadwinner couple (as opposed to a malebreadwinner couple) compared to women with a medium level of education.

Regarding the regional-level variables, we find a positive and significant association between regional unemployment rate and the probability of being in a female-breadwinner or equal-income couple. As the male unemployment rate in the region of residence increases, the probability that the respondent belongs to an equalincome or female-breadwinner couple also increases.

We also find a positive and significant association between the prevalence of gender-egalitarian values in a region and the probability of being in an equal-income versus a male-breadwinner couple. We do not find any association between the regional-level gender equality index and the prevalence of female-breadwinner couples. Finally, the variable measuring female labour force participation in the region of residence is not significantly associated with the couple type, once the other variables are controlled for.

We conclude that the regional context is important when explaining partners' contributions to the household income. 
Table 1: Coefficient estimates from the three-level multinomial logistic regression model predicting the couple type (reference: malebreadwinner couple)

\begin{tabular}{|c|c|c|}
\hline & Female breadwinner & Equal income \\
\hline \multirow[t]{2}{*}{ Gender of respondent (ref. Male) } & $-0.485^{\star \star \star}$ & $-0.329^{\star \star \star}$ \\
\hline & $(0.056)$ & $(0.046)$ \\
\hline \multirow[t]{2}{*}{ Age } & $0.078^{*}$ & $0.087^{* *}$ \\
\hline & $(0.039)$ & $(0.033)$ \\
\hline \multirow[t]{2}{*}{$\mathrm{Age}^{2}$} & -0.001 & $-0.001^{* *}$ \\
\hline & $(0.000)$ & $(0.000)$ \\
\hline \multicolumn{3}{|c|}{ Age difference between partners (ref. Man older) } \\
\hline \multirow[t]{2}{*}{ Equal age } & 0.057 & 0.065 \\
\hline & $(0.057)$ & $(0.047)$ \\
\hline \multirow[t]{2}{*}{ Woman older } & $0.305^{\star *}$ & 0.166 \\
\hline & $(0.103)$ & $(0.089)$ \\
\hline \multicolumn{3}{|l|}{ Woman's education (ref. Low) } \\
\hline \multirow[t]{2}{*}{ Medium } & $-0.222^{*}$ & $0.159^{*}$ \\
\hline & $(0.089)$ & $(0.077)$ \\
\hline \multirow[t]{2}{*}{ High } & $0.203^{*}$ & $0.532^{\star \star \star}$ \\
\hline & $(0.090)$ & $(0.079)$ \\
\hline \multicolumn{3}{|c|}{ Education difference between partners (ref. Man more educated) } \\
\hline \multirow[t]{2}{*}{ Equally educated } & $0.278^{\star * *}$ & $0.349^{* \star \star}$ \\
\hline & $(0.077)$ & $(0.062)$ \\
\hline \multirow[t]{2}{*}{ Woman more educated } & $0.811^{\star \star *}$ & $0.572^{\star \star \star}$ \\
\hline & $(0.082)$ & $(0.068)$ \\
\hline \multirow[t]{2}{*}{ Number of children in household } & $-0.242^{\star \star \star}$ & $-0.275^{\star \star \star}$ \\
\hline & $(0.030)$ & $(0.025)$ \\
\hline \multirow[t]{2}{*}{ Living in urban area (ref. rural) } & $0.210^{* \star *}$ & -0.021 \\
\hline & $(0.059)$ & $(0.048)$ \\
\hline \multirow[t]{2}{*}{ Regional male unemployment rate } & $0.040^{\star \star *}$ & $0.030^{* *}$ \\
\hline & $(0.011)$ & $(0.011)$ \\
\hline \multirow[t]{2}{*}{ Regional gender equality index } & 0.001 & $0.011^{\star * \star}$ \\
\hline & $(0.003)$ & $(0.002)$ \\
\hline \multirow[t]{2}{*}{ Regional female labour force participation } & 0.001 & -0.002 \\
\hline & $(0.009)$ & $(0.008)$ \\
\hline \multirow[t]{2}{*}{ Constant } & $-3.906^{\star \star \star}$ & $-3.714^{\star \star \star}$ \\
\hline & $(0.921)$ & $(0.800)$ \\
\hline \multicolumn{3}{|l|}{ Random effects } \\
\hline \multirow[t]{2}{*}{ Variance of country effect } & 0.106 & \\
\hline & $(0.036)$ & \\
\hline \multirow[t]{2}{*}{ Variance of region effect } & 0.026 & \\
\hline & $(0.013)$ & \\
\hline$N$. & 12,822 & \\
\hline
\end{tabular}

p-value: ${ }^{* * *}<0.001 ;{ }^{* *}<0.01 ;{ }^{*}<0.05$. 


\subsection{Predicted probabilities}

To better interpretate the results, we complement the estimation table with two types of graphical representation. Predicted probabilities allow us to show variability in couples' income arrangements, adjusting for individual-level variables. In computing the predicted probabilities, all control variables are set to the observed values, while country- and region-random effects are set at the mean value (i.e., zero). For each outcome category (male-breadwinner couple, female-breadwinner couple, equal-income couple) we calculate average regional predicted probabilities and plot their distributions using choropleth maps. We divide their ranges into four equal groups, using quartiles. The resulting intervals can be interpreted as groups of regions with low, medium-low, medium-high, and high prevalence of each couple type. The advantage of using predicted probabilities rather than observed values is that the former allows adjusting for individual-level characteristics and obtaining a smoothed representation of the outcome. Observed proportions may be unreliable, especially in regions with very small sample sizes, whereas regional-specific predictions from a random effects model 'borrow strengths' from other regions.

The first graphical representation (Figures 3, 5, and 7) presents a scatterplot of the two regional-level explanatory variables of interest: the regional gender equality index (x-axis) versus the regional male unemployment rate (y-axis). The dots in the scatterplot represent the 192 ESS regions and are organized into four groups representing the quartiles of the distribution of the predicted probability of observing a given couple type. For each combination of regional male unemployment and gender equality, we can identify whether the predicted probability of observing a given couple type in that region is low, medium-low, medium-high, or high. This graph allows evaluating the relative contribution of the two main contextual explanatory variables to explaining the prevalence of a specific couple type across regions.

The second graphical representation (Figures 4, 6, and 8) presents a choropleth map showing the average predicted probabilities of observing a given couple type across the 192 ESS regions. As for the first type of graphical representation, the predicted probabilities are divided into four groups according to the distribution's quartiles. These maps make it possible to visually assess which regions and countries have a high prevalence of male-breadwinner, female-breadwinner, and equal-income couples, and whether the average predicted probabilities of observing the three couple types vary across regions within countries. 


\subsubsection{The contextual correlates of male-breadwinner couples}

Figure 3 shows that the average predicted probability of male-breadwinner couples varies with both regional male unemployment and gender equality. The association with gender equality is particularly strong: as gender equality increases, the predicted probability of observing male-breadwinner couples declines. All regions characterized by a low predicted probability of male-breadwinner couples are also characterized by medium-high levels of gender equality. The association with regional male unemployment is instead weaker. Regions characterized by low male unemployment show a high predicted probability of observing male-breadwinner couples (bottom-left corner), and regions characterized by high male unemployment show a low prevalence of male-breadwinner families (top-right corner). Instead, for medium-low and mediumhigh levels of male unemployment the predicted probability of observing malebreadwinner couples assumes all possible values in its range.

The map in Figure 4 shows that the predicted probabilities of observing malebreadwinner couples differ markedly across European regions. The map allows identifying the regions characterized by a high prevalence of male-breadwinner couples. These areas are mainly concentrated in the Southern and Eastern European countries. Cyprus, Israel, Ukraine, and several Hungarian, Polish, Czech, Slovak, Greek, and Portuguese regions show a high or medium-high predicted probability of observing male-breadwinner couples. Other regions showing a high predicted probability of male-breadwinner couples are found in Switzerland, Germany, and Belgium. Norwegian regions show a medium-low-to-medium-high predicted probability of observing male-breadwinner couples, with the exception of the Oslo area. The predicted probabilities of observing male-breadwinner couples are especially low in Finland, Estonia, Ireland, East Germany, Scotland, Northern England, and most regions of Spain and Denmark.

In some countries we find only limited within-country variability in the probability of male-breadwinner couples. This is the case in the Scandinavian countries, Czech Republic, Hungary, Switzerland, and Ireland. In other countries, however, we do find a high degree of variability. For example, in Germany the predicted probability of observing male-breadwinner couples is in the top $25 \%$ of the sample distribution (top quartile) in the Western regions of Bayern, Saarland, and Niedersachsen, while it is in the bottom $25 \%$ of the sample distribution (bottom quartile) in all the Eastern regions and in Bremen and Schleswig-Holstein. Similar within-country differences exist in France, the UK, Poland, and Greece. ${ }^{8}$

\footnotetext{
${ }^{8}$ The predicted probability of observing male-breadwinner couples in France is lowest in the regions of Picardie, Limousin, and Provence-Alpes-Cote D'Azur and highest in Basse-Normandie and Franche-Comte; in the UK it is lowest in Scotland, the North East, London, and Yorkshire and The Humber, and highest in the
} 


\section{Figure 3: Average regional predicted probability of observing male- breadwinner couples across ESS regions, by regional male unemployment and regional gender equality}

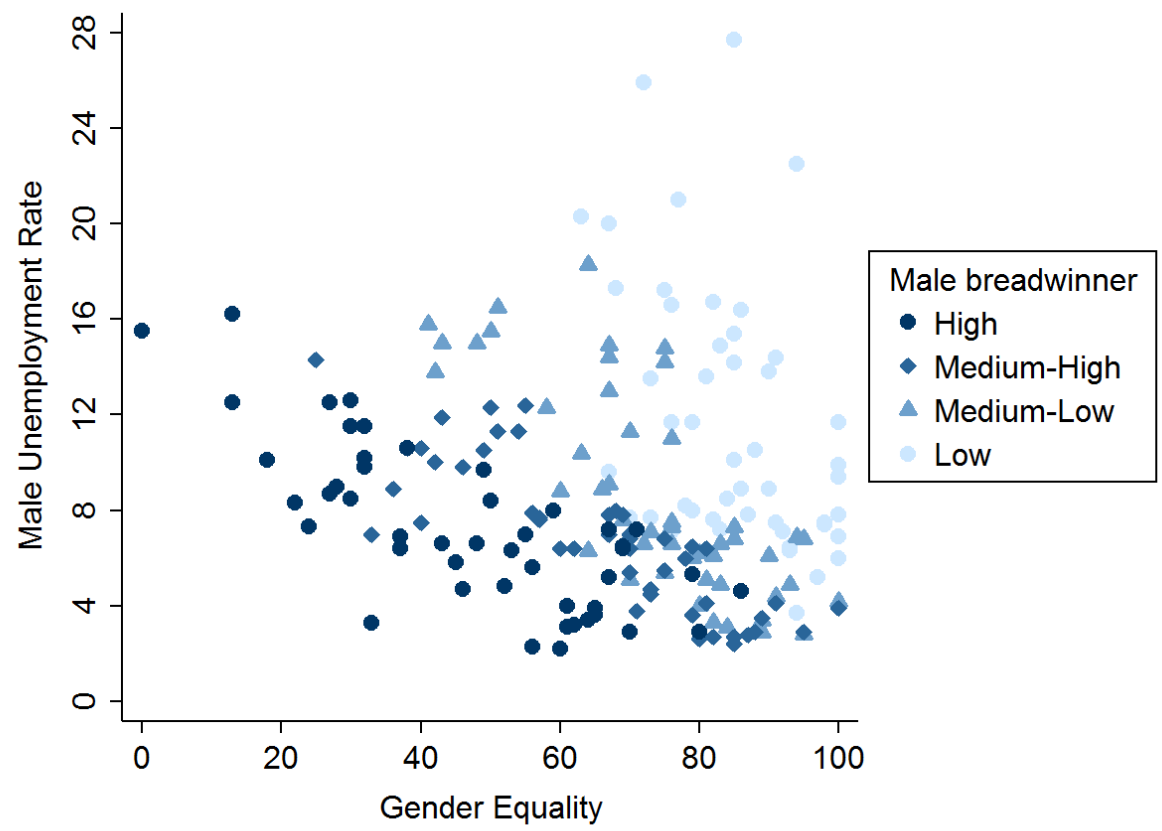

Note: The average predicted probability of observing a low (44-59\%), medium-low (60-64\%), medium-high (65-66.5\%) and high (66.6-78\%) prevalence of male-breadwinner couples in each ESS region is obtained by estimating a three-level multinomial logistic regression model predicting the couple type (male-breadwinner, female-breadwinner and equal-income couple). The four groups of predicted probabilities refer to the four quartiles.

East of England; in Poland it is lowest in Opolskie, Pomorskie, and Dolnoslaskie and highest in Wielkopolskie, Malopolskie, Kujawsko-Pomorskie, and Podkarpackie; in Greece it is lowest in Dytiki Makedonia and highest in Notio Aigaio, Thessalia, Sterea Ellada, Peloponnisos, Dytiki Ellada, Kriti, and Ionia Nisia. 
Figure 4: Map of average predicted probabilities of observing malebreadwinner couples across ESS regions

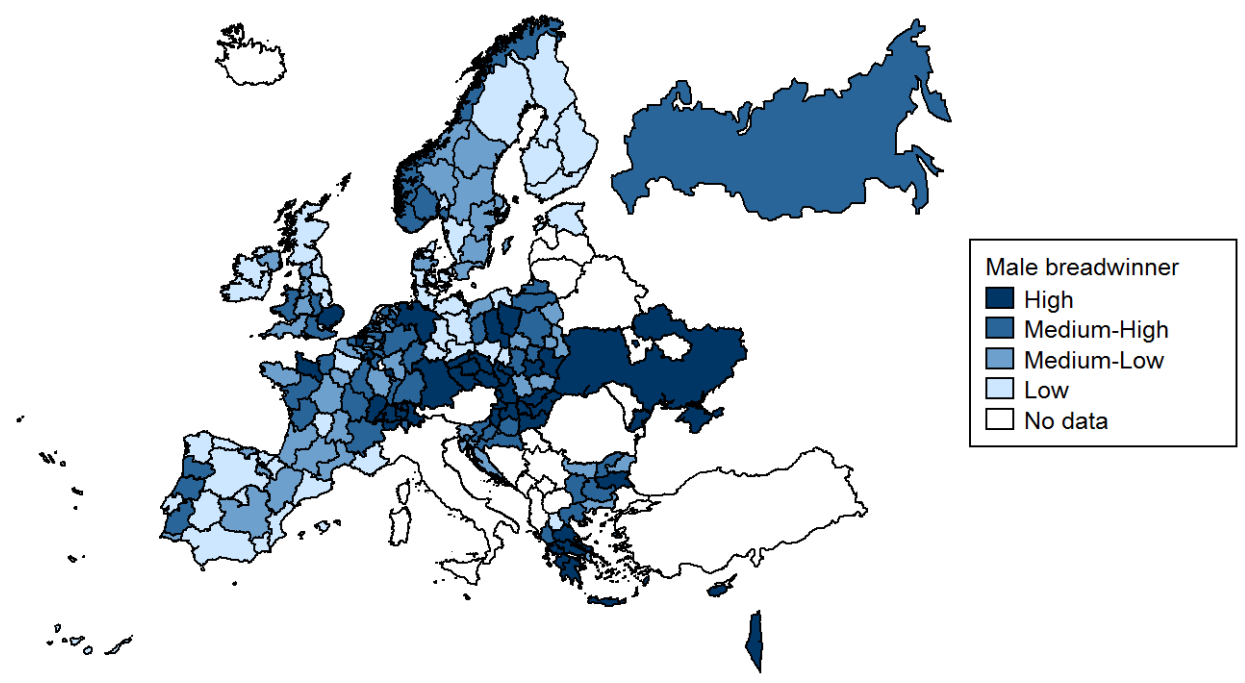

Note: See note in Figure 3.

\subsubsection{The contextual correlates of female-breadwinner couples}

Consistent with the estimates in Table 1, Figure 5 shows that the prevalence of femalebreadwinner couples varies considerably with the regional male unemployment rate, whereas it is independent of gender equality. The group that shows the lowest values of the predicted probability of female-breadwinner couples is found in the bottom part of Figure 5. This group is characterised by low levels of male unemployment rate, while gender equality assumes all possible values in the observed range. The group that shows the highest values of the predicted probability of female-breadwinner couples is found in the top part of the figure. This group is characterized by high levels of male unemployment rate but also by high levels of gender equality.

The map in Figure 6 shows that the highest predicted probabilities of observing female-breadwinner couples are found in Southern and Eastern Europe and Ireland. 
Vitali \& Arpino: The influence of context on partners' contributions to the household income

Spanish regions lead the ranking: The predicted probability of observing femalebreadwinner couples is 23\% in Canarias, 20\% in Andalucía, and between $18 \%$ and $19 \%$ in Comunidad Valenciana, Illes Balears, Murcia, and Extremadura. High values of the predicted probability of female-breadwinner couples are also found in Estonia (18\%), Brussels, the Greek region of Attiki, and the Portuguese region of Lisbon (all equal to $17 \%)$, the French region of Provence-Alpes-Cote D'Azur (16\%), Berlin (17\%) and Sachsen-Anhalt in Germany (15\%), Scotland (16\%), and the English regions of London, West Midlands, and Yorkshire (all equal to 15\%).

The pattern of female-breadwinner couples observed in Figure 5 matches the pattern of male unemployment rate observed in Figure 1. In fact, all regions characterized by a high predicted probability of female-breadwinner couples are also characterized by a high or a medium-high level of male unemployment, with only a few exceptions, i.e., London, Russia, and Ukraine, where the male unemployment rate is medium-low. This result reinforces the finding that the variation in the prevalence of female-breadwinner couples across regions can be explained by variation in the male unemployment rate.

Figure 6 also shows that the within-country variability in the prevalence of femalebreadwinner couples is high in some countries while low or absent in others. For example, all the Swiss regions homogeneously show low predicted probabilities of observing female-breadwinner couples, while the predicted probabilities are homogeneously high-to-medium-high in Spain, Greece, and Bulgaria, low-to-mediumlow in the Netherlands, and medium in the Scandinavian countries, with the exception of Norway. Norwegian regions show a lower prevalence of female-breadwinner couples than the other Nordic countries, except for the Oslo area. Germany, again, stands out as a country showing a high degree of internal variability: the predicted probability of observing female-breadwinner couples is among the highest in the sample in the Eastern regions of Berlin and Sachsen-Anhalt and among the lowest in the Western regions of Bayern, Saarland and Hessen, Baden-Württemberg, and Niedersachsen. Other countries showing internal variation in the prevalence of female-breadwinner couples are Poland, Spain, the UK, and France. ${ }^{9}$

Figure 6 also shows that some regions in a given country are more similar to regions in a different (often neighbouring) country than to other regions in the same

\footnotetext{
${ }^{9}$ The predicted probability of observing female-breadwinner couples in Poland is lowest in the region of Kujawsko-Pomorskie and highest in Pomorskie, Podlaskie, Zachodniopomorskie, Lubuskie, and Dolnoslaskie; in France it is lowest in Franche-Comte, Basse Normandie, Rhone-Alpes, Lorraine, Champagne-Ardenne, and Limousin and highest in Provence-Alpes-Cote D'Azur; in the UK it is lowest in the East of England and highest in Yorkshire and the Humber, West Midlands, London, and Scotland; in Belgium it is lowest in most regions with the exception of Liege, Hainaut, and the Brussels region; in Spain it is lowest in the Comunidad Foral de Navarra, medium-high in Melilla and Aragon, and high in the remaining 15 regions.
} 
country. In several cases we find clusters of regions that cross country borders; e.g., between Finland and Sweden, East Germany and Poland, and France and Spain.

\section{Figure 5: Average regional predicted probability of observing female- breadwinner couples, by regional male unemployment and regional gender equality}

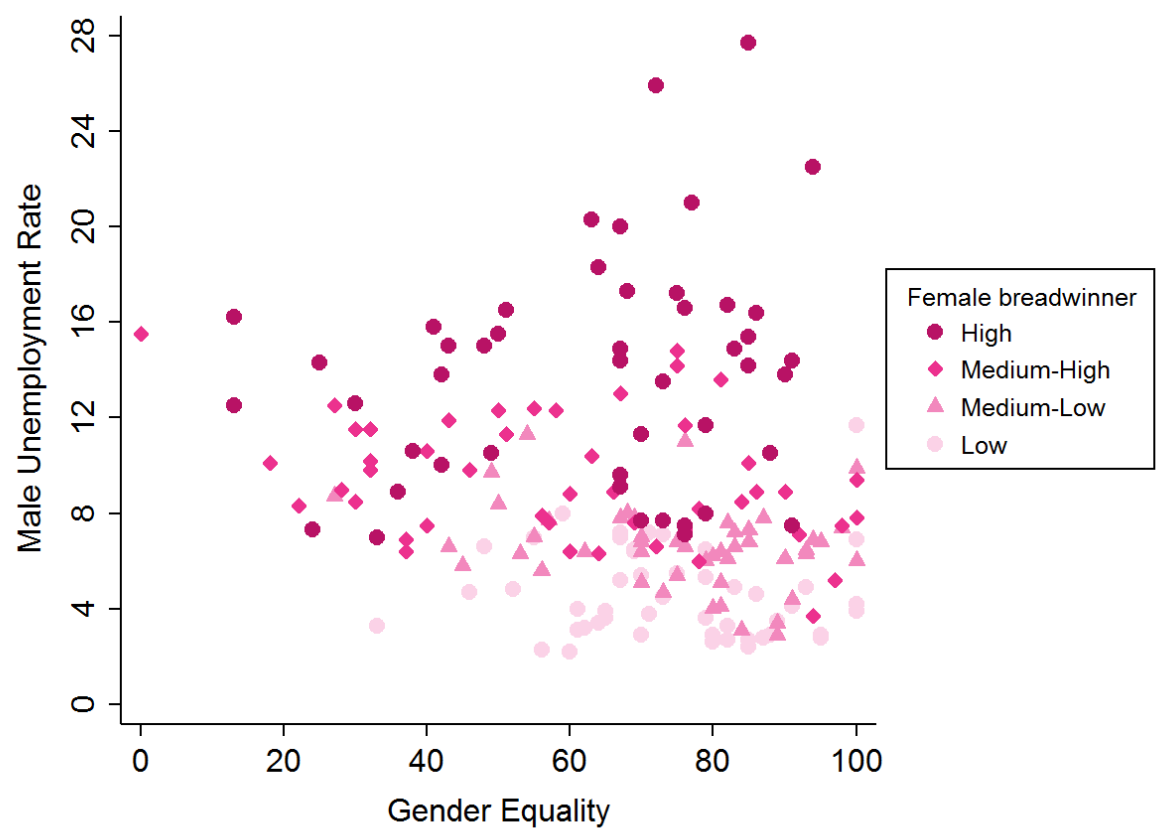

Note: The average predicted probability of observing a low (9-12.1\%), medium-low (12.2-13.4\%), medium-high (13.5-14\%), and high (15-23\%) prevalence of female-breadwinner couples in each ESS region is obtained by estimating a three-level multinomial logistic regression model predicting the couple type (male-breadwinner, female-breadwinner and equal-income couple). The four groups of predicted probabilities refer to the four quartiles. 
Figure 6: Map of average predicted probabilities of observing femalebreadwinner couples

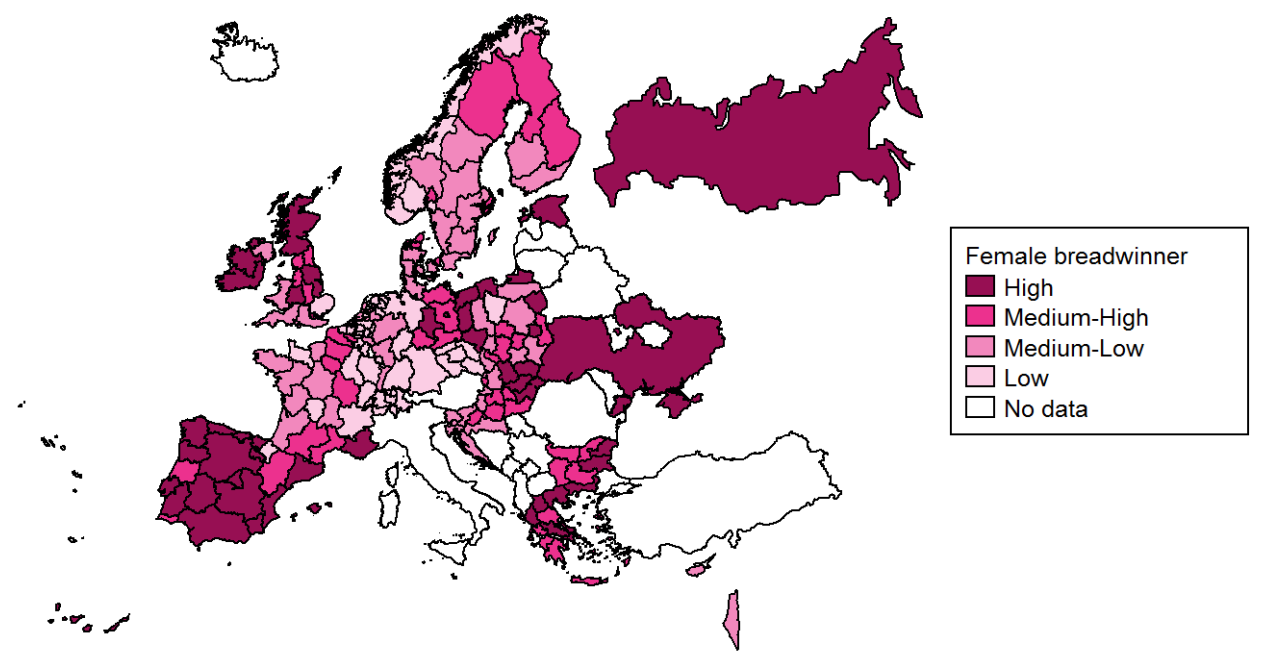

Note: See note in Figure 5.

\subsubsection{The contextual correlates of equal-income couples}

Figure 7 shows the average predicted probability of observing equal-income couples. This probability varies strongly with the level of gender equality, while it is weakly influenced by the level of male unemployment rate in the region. 
Figure 7: Average regional predicted probability of observing equal-income couples, by regional male unemployment and regional gender equality

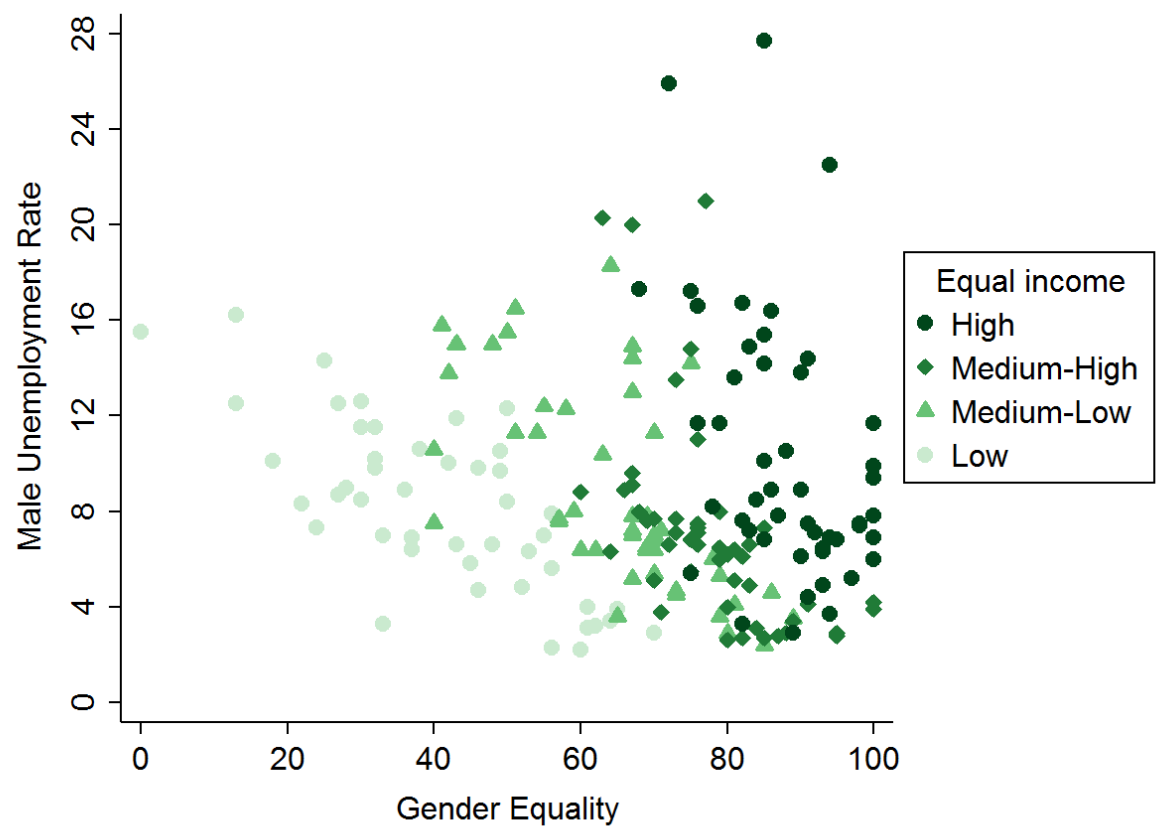

Note: The average predicted probability of observing a low (8-20\%), medium-low (21.1-23\%), medium-high (24-27\%) and high $(28-34 \%)$ prevalence of equal-income couples in each ESS region is obtained by estimating a three-level multinomial logistic regression model predicting the couple type (male-breadwinner, female-breadwinner and equal-income couple). The four groups of predicted probabilities refer to the four quartiles.

Figure 8 shows that equal-income couples are especially widespread in the Scandinavian countries, Ireland, Estonia, East Germany, and parts of Spain, France, and the UK. The French regions of Limousin and Picardie lead the ranking (34\%), followed by the German region of Bremen (33\%) and the Spanish regions of Canarias, Murcia, Madrid, Asturias, and Castilla y Leon (between 31\% and 33\%). The prevalence of equal-income couples is limited in Eastern Europe, Greece, Cyprus, and Israel. The pattern of equal-income couples observed in Figure 8 matches the pattern of gender equality observed in Figure 2. All regions characterized by a high predicted probability of equal-income couples are also characterized by a high or a medium-high level in the 
gender equality index, the only exception being Estonia, which scores medium-low in terms of gender equality but high in terms of prevalence of equal-income couples.

Finally, some countries show a homogeneous prevalence of equal-income couples across regions, i.e., high in Denmark, Finland, and Ireland, high-to-medium-high in Sweden, medium-high in Slovenia, low in Hungary, and low-to-medium-low in Czech Republic, Bulgaria, and Slovakia. Other countries are characterized by great internal variability. ${ }^{10}$

\section{Figure 8: Map of average predicted probabilities of observing equal-income couples}

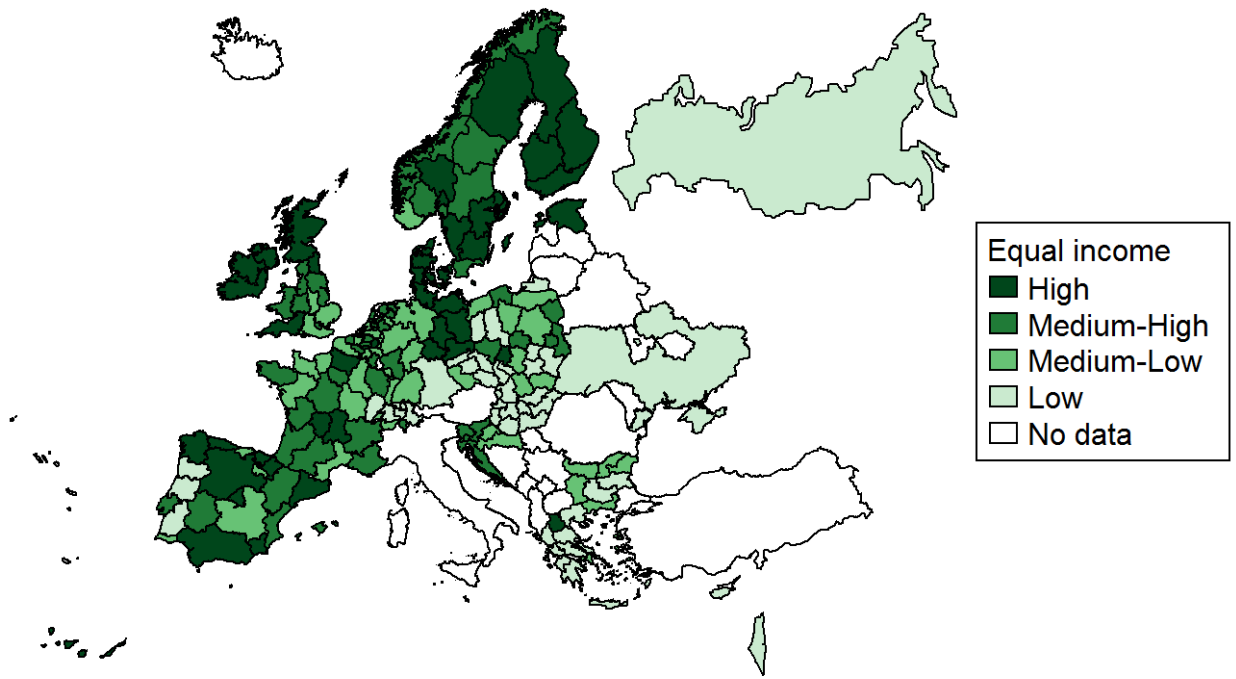

Note: See note in Figure 7.

${ }^{10}$ The predicted probability of observing equal-income couples in Germany is lowest in the Bayern region and highest in the regions of Sachsen, Thüringen, Sachsen-Anhalt, Schleswig-Holstein, Brandenburg, Berlin, Mecklenburg-Vorpommern, and Bremen; in Poland it is lowest in Podkarpackie, Lubuskie, Wielkopolskie, Malopolskie, and Swietokrzyskie and highest in Opolskie (29\%); in Greece it is lowest in the majority of regions, medium-low in Voreio Aigaio, Attiki, and Anatoliki Makedonia and Thraki, and highest in Dytiki Makedonia (28\%); in France it is lowest in Franche-Comte and highest in Auvergne, Picardie, and Limousin. 


\section{Conclusions}

This paper analyses the spatial distribution of partners' contribution to household income in Europe and investigates the contextual correlates of female-breadwinner, male-breadwinner, and equal-income couples across European countries and regions.

We developed and tested two hypotheses for explaining the varying prevalence of female-breadwinner, male-breadwinner, and equal-income couples across European regions. First, we expected female-breadwinner and equal-income couples to be driven by gender equality and hence to be especially widespread in those regions characterized by a high prevalence of gender-egalitarian attitudes. Second, we expected femalebreadwinner and equal-income couples to be driven by economic necessity and hence to be especially widespread in those regions characterized by high male unemployment.

Our results show that the prevalence of female-breadwinner couples in Europe is associated with male unemployment and not with the diffusion of gender-egalitarian attitudes. The higher the male unemployment rate in the region of residence, the higher the likelihood of observing a high prevalence of female-breadwinner couples in the region. We found female-breadwinner families to be especially widespread in countries and regions showing a high male unemployment rate, such as Spain, Ireland, EasternEuropean countries, parts of Greece, and the UK.

Our results do not support the hypothesis that a higher prevalence of femalebreadwinner couples is more likely in those contexts where gender equality is higher. Among the forty-eight regions showing the highest prevalence of female-breadwinner couples in the sample (i.e., the top quartile), only nine are characterized by high levels of gender equality. Instead, thirty-two of these regions are characterized by high levels of male unemployment. Hence, we conclude that gender equality fails to explain the prevalence of female-breadwinner couples.

Instead, we found that gender-egalitarian attitudes encourage equality among partners in terms of their contribution to household income. In other words, equalincome couples are more likely to be observed in those regions that score high in terms of gender equality; i.e., in Scandinavian countries, Ireland, Estonia, East Germany, parts of Spain, France, and the UK. Results show that the prevalence of equal-income couples is only marginally associated with regional male unemployment rate.

Under perfect gender equality between partners, we would expect to find a high prevalence of equal-income couples and a similar prevalence of female- and malebreadwinner couples. Previous research has shown a decline in the male-breadwinnerfemale-homemaker model and an increase in dual-income couples during past decades. Yet our results show that, throughout Europe, couples where the man is the main income provider are still very widespread: much more widespread than couples where the woman is the main income provider. Also, in the Scandinavian countries (in 
particular Norway) we find that men are the main income providers in more than onein-two couples, even though these countries rank high in terms of gender equality and female labour force participation.

Finally, we have shown that the prevalence of the three couple types varies not only across European countries but also across regions within countries. Our three-level analysis allows for the identification of regions characterized by high prevalence of one specific couple type, which would be impossible to discern in a country-level analysis. This is the case, for example, for Eastern Germany, which is characterized by a high prevalence of female-breadwinner and equal-income couples, in stark contrast to the rest of the country where such couple types are much less widespread.

The results in this paper suggest that the rise in female-breadwinner couples observed during the economic crisis is mainly attributable to the business cycle and is driven by economic necessity rather than genuine choice. The economic revolution, which, according to Ruggles (2015), was responsible for demographic changes in family composition, divorce, and marriage, appears to also provide an explanation for the observed prevalence of female-breadwinner couples. In other words, changes in the labour market which have affected men's and women's economic prospects provide a better explanation of the observed pattern of women's economic superiority with respect to their partners than the diffusion of gender-egalitarian attitudes. Our results are in line with research by Gerson (2010), which shows that young generations of women and men expect to achieve gender equality in work and care; however, institutional obstacles such as demanding workplaces and unavailable or unaffordable childcare hold them back. Similarly, Cherlin (2016) suggests that the new "genderegalitarian equilibrium" described by Esping-Andersen and Billari (2015) and Goldscheider, Bernhardt, and Lappegård (2015) may not be accessible to all, but may be an option open only to the highly educated strata of the population, which are less likely to be exposed to economic difficulty.

It should be noted that our data refer to 2010-2011, a period of economic recession in Europe. Hence we could question whether the weak association between genderegalitarian attitudes and the prevalence of female-breadwinner couples that we have documented is specific to the period analysed. In other words, it may be that during the recession the effect of male unemployment dominates and blurs the effect of genderegalitarian attitudes. Similarly, we could ask whether the prevalence of femalebreadwinner couples will decline once the economic conditions for men have improved, and if a new spatial distribution of the three couple types will emerge after the economic crisis. We know from previous research that female-breadwinner couples driven by economic necessity tend to be only a temporary arrangement, whereas they tend to be a permanent arrangement when driven by gender-egalitarian attitudes 
(Drago, Black, and Wooden 2005). Our data did not allow us to incorporate information on the persistency of the income arrangement over time.

Our study has other limitations. First, we did not separate women who are the sole income provider from women who are the main earner. Using household-level income data, Klesment and Van Bavel (2015) and Bertrand, Kamenica, and Pan (2015) show heterogeneity among the category of female breadwinners in terms of what percentage of household income they provide. While we find no correlation between genderegalitarian attitudes and the prevalence of female-breadwinner couples, we cannot rule out the possibility that gender-egalitarian attitudes may be correlated with the prevalence of a subgroup of female breadwinners, e.g., those who are the sole income provider in the household or those who contribute just above $50 \%$ of their total household income. The European Social Survey data and its sample size do not make it possible to answer these questions, which we leave to future research.

We also acknowledge the limitations of a study on partners' contribution to household income based on social survey data. In particular, the measure used to capture the partners' contribution to household income is self-reported and may be biased depending on the gender of the respondent (see e.g., Singh, Kalliath, and Kalliath 2010). The cross-national nature of the data presents further limitations. First, the data does not allow taking into account that the couples' income arrangements may change over time. Second, we are unable to account for selection into partnership and partnership stability and duration, despite the fact that such processes may influence couples' income arrangements and be influenced by contextual gender-egalitarian attitudes. Previous research has shown that in contexts characterized by a low prevalence of gender-egalitarian attitudes, such as Southern Europe or Germany, higheducated gender-egalitarian women are less likely to be partnered when compared to lower-educated women (Sevilla-Sanz 2010; Kalmijn 2013), and female-breadwinner couples face a higher risk of union dissolution than other couple types (Cooke 2006). By contrast, high-educated women have the highest chances of being in a union in gender-egalitarian Northern European countries (Kalmijn 2013) and the risk of union dissolution does not vary across couple types (Esping-Andersen and Holm 2014). Future studies can address these issues by using longitudinal data.

\section{Acknowledgements}

The authors would like to thank participants in the session 'Consequences of Domestic Gender Equality' at the 2015 Annual Meeting of the Population Association of America, in the 2016 Workshop on 'Female-Breadwinner Families in Europe', and in the Social Science Seminar at UCL Institute of Education, along with two anonymous 
reviewers for their valuable comments. The authors would also like to thank the European Social Survey Support Team and Juan Galeano for their valuable help with shapefiles. Agnese Vitali gratefully acknowledges the support received by the UK Economic and Social Research Council under the Future Research Leaders scheme grant number ES/N00082X/1. 


\section{References}

Aassve, A., Arpino, B., and Billari, F.C. (2013). Age norms on leaving home: Multilevel evidence from the European Social Survey. Environment and Planning A 45(2): 383-401. doi:10.1068/a4563.

Aassve, A., Fuochi, G., and Mencarini, L. (2014). Desperate housework: Relative resources, time availability, economic dependency, and gender ideology across Europe. Journal of Family Issues 35(8): 1000-1022. doi:10.1177/0192513X 14522248 .

Arpino, B. and Tavares, L.P. (2013). Fertility and values in Italy and Spain: A look at regional differences within the European context. Population Review 52(1): 6286.

Arpino, B., Esping-Andersen, G., and Pessin, L. (2015). Changes in gender role attitudes and fertility: A macro-level analysis. European Sociological Review 31(3): 370-382. doi:10.1093/esr/jcv002.

Baxter, J. and Kane, E.W. (1995). Dependence and independence: A cross-national analysis of gender inequality and gender attitudes. Gender \& Society 9(2): 193215. doi:10.1177/089124395009002004.

Becker, G.S. (1981). A treatise on the family. Cambridge: Harvard University Press.

Bernhardt, A., Morris, M., and Handcock, M.S. (1995). Women's gains or men's losses? A closer look at the shrinking gender gap in earnings. American Journal of Sociology 101(2): 302-328. doi:10.1086/230726.

Bertrand, M., Kamenica, E., and Pan, J. (2015). Gender identity and relative income within households. The Quarterly Journal of Economics 130(2): 571-614. doi:10.1093/qje/qjv001.

Bettio, F., Corsi, M., D’Ippoliti, C., Lyberaki, A., Lodovici, M.S., and Verashchagina, A. (2012). The impact of the economic crisis on the situation of women and men and on gender equality policies. Brussels: European Commission.

Bianchi, S.M., Casper, L.M., and Peltola, P.K. (1999). A cross-national look at married women's earnings dependency. Gender Issues 17(3): 3-33. doi:10.1007/s12147999-0001-0.

Bianchi, S.M., Milkie, M.A., Sayer, L.C., and Robinson, J.P. (2000). Is anyone doing the housework? Trends in the gender division of household labor. Social Forces 79(1): 191-228. doi:10.1093/sf/79.1.191. 
Vitali \& Arpino: The influence of context on partners' contributions to the household income

Bloemen, H.G. and Stancanelli, E.G. (2013). Toyboys or supergirls? An analysis of partners' employment outcomes when she outearns him. Review of Economics of the Household 13(3): 501-530. doi:10.1007/s11150-013-9212-y.

Blossfeld, H.P. and Drobnic, S. (2001). Careers of couples in contemporary societies: From male breadwinner to dual breadwinner families. Oxford: Oxford University Press.

Blossfeld, H.P., Klijzing, E., Mills, M., and Kurz, K. (eds.) (2006). Globalization, uncertainty and youth in society: The losers in a globalizing world. London: Routledge.

Breen, R. and Cooke, L.P. (2005). The persistence of the gendered division of domestic labour. European Sociological Review 21(1): 43-57. doi:10.1093/esr/jci003.

Cha, Y. and Thébaud, S. (2009). Labor markets, breadwinning, and beliefs how economic context shapes men's gender ideology. Gender \& Society 23(2): 215243. doi: $10.1177 / 0891243208330448$.

Cherlin, A.J. (2016). A happy ending to a half-century of family change? Population and Development Review 42(1): 121-129. doi:10.1111/j.1728-4457.2016.0011 1.x.

Cho, Y. and Newhouse, D. (2012). How did the great recession affect different types of workers? Evidence from 17 middle-income countries. World Development 41: 31-50. doi:10.1016/j.worlddev.2012.06.003.

Cooke, L.P. (2006). 'Doing' gender in context: Household bargaining and risk of divorce in Germany and the United States. American Journal of Sociology 112(2): 442-472. doi:10.1086/506417.

Cory, G. and Stirling, A. (2015). Who's breadwinning in Europe? A comparative analysis of maternal breadwinning in Great Britain and Germany. London: Institute for Public Policy Research (IPPR). http://www.ippr.org/publications/ whos-breadwinning-in-europe.

Drago, R., Black, D., and Wooden, M. (2005). Female breadwinner families: Their existence, persistence and sources. Journal of Sociology 41(4): 343-362. doi: $10.1177 / 1440783305058465$.

Esping-Andersen, G. (2009). The incomplete revolution: Adapting to women's new roles. Cambridge: Polity Press. 
Esping-Andersen, G. and Billari, F.C. (2015). Re-theorizing family demographics. Population and Development Review 41(1): 1-31. doi:10.1111/j.1728-4457.20 15.00024.x.

Esping-Andersen, G. and Holm, A. (2014). Gendered income dominance and partner instability. Paper presented at the European Population Conference, Budapest.

Gerson, K. (2010). The unfinished revolution: How a new generation is reshaping family, work, and gender in America. New York: Oxford University Press.

Goldin, C. (2006). The quiet revolution that transformed women's employment, education, and family. American Economic Review 96(2): 1-21. doi:10.1257/0 00282806777212350 .

Goldscheider, F., Bernhardt, E., and Lappegård, T. (2015). The gender revolution: A framework for understanding changing family and demographic behavior. Population and Development Review 41(2): 207-239. doi:10.1111/j.1728-4457. 2015.00045.x.

Hakim, C. (2000). Work-lifestyle choices in the 21st century: Preference theory. Oxford: Oxford University Press.

Harkness, S. (2013). Women, families and the 'Great Recession' in the UK. In: Ramia, G., Farnsworth, K., and Irving, Z. (eds). Social policy review 25: Analysis and debate in social policy. Bristol: Policy Press. doi:10.1332/policypress/9781447 312741.003.0015.

Harkness, S. and Evans, M. (2011). The employment effects of recession on couples in the UK: Women's and household employment prospects and partners' job loss. Journal of Social Policy 40(4): 675-693. doi:10.1017/S0047279411000201.

Hoynes, H., Miller, D.L., and Schaller, J. (2012). Who suffers during recessions? The Journal of Economic Perspectives 26(3): 27-47. doi:10.3386/w17951.

Kalmijn, M. (2013). The educational gradient in marriage: A comparison of 25 European countries. Demography 50(4): 1499-1520. doi:10.1007/s13524-0130229-x.

Klesment, M. and Van Bavel, J. (2015). The reversal of the gender gap in education and female breadwinners in Europe. Stockholm: Families and Societies, Stockholm University (Families and Societies working paper 26).

Lesthaeghe, R.J. and Neidert, L. (2006). The second demographic transition in the United States: Exception or textbook example? Population and Development Review 32(4): 669-698. doi:10.1111/j.1728-4457.2006.00146.x. 
Vitali \& Arpino: The influence of context on partners' contributions to the household income

McDonald, P. (2013). Societal foundations for explaining fertility: Gender equality. Demographic Research 28(34): 981-994. doi:10.4054/DemRes.2013.28.34.

Oppenheimer, V.K. (1994). Women's rising employment and the future of the family in industrial societies. Population and Development Review 20(2): 293-342. doi: $10.2307 / 2137521$.

Raley, S.B., Mattingly, M.J., and Bianchi, S.M. (2006). How dual are dual-income couples? Documenting change from 1970 to 2001. Journal of Marriage and Family 68(1): 11-28. doi:10.1111/j.1741-3737.2006.00230.x.

Ruggles, S. (2015). Patriarchy, power, and pay: The transformation of American families, 1800-2015. Demography 52(6): 1797-1823. doi:10.1007/s13524-015$0440-\mathrm{z}$.

Schneider, D. (2011). Market earnings and household work: New tests of gender performance theory. Journal of Marriage and Family 73(4): 845-860. doi:10.1111/j.1741-3737.2011.00851.x.

Schwartz, C.R. and Han, H. (2014). The reversal of the gender gap in education and trends in marital dissolution. American Sociological Review 79(4): 605-629. doi:10.1177/0003122414539682.

Sevilla-Sanz, A. (2010). Household division of labor and cross-country differences in household formation rates. Journal of Population Economics 23(1): 225-249. doi:10.1007/s00148-009-0254-7.

Singh, V., Kalliath, T., and Kalliath, P. (2010). Dual-income marital dyads and mutually discrepant economic versus personal information: An exploratory investigation. Psychological Studies 55(3): 263-269. doi:10.1007/s12646-0100029-y.

Sironi, M. and Furstenberg, F.F. (2012). Trends in the economic independence of young adults in the United States: 1973-2007. Population and Development Review 38(4): 609-630. doi:10.1111/j.1728-4457.2012.00529.x.

Smith, K. (2009). Increased reliance on wives as breadwinners during the first year of the recession. Durham: The Carsey Institute, University of New Hampshire (Issue brief no. 9).

Tichenor, V. (2005). Maintaining men's dominance: Negotiating identity and power when she earns more. Sex Roles 53(3-4): 191-205. doi:10.1007/s11199-005$5678-2$. 
Van Bavel, J. (2012). The reversal of gender inequality in education, union formation and fertility in Europe. Vienna Yearbook of Population Research 10: 127-154.

Vitali, A. and Mendola, D. (2014). The emergence of women as main earners in Europe. Southhampton: ESRC Centre for Population Change (Working paper $56)$.

Vitali, A., Aassve, A., and Lappegård, T. (2015). Diffusion of childbearing within cohabitation. Demography 52(2): 355-377. doi:10.1007/s13524-015-0380-7.

Wang, W., Parker, K., and Taylor, P. (2013). Breadwinner moms. Washington, D.C.: Pew Research Center. http://www.pewsocialtrends.org/2013/05/29/breadwinnermoms.

Warren, T. (2007). Conceptualizing breadwinning work. Work, Employment \& Society 21(2): 317-336. doi:10.1177/0950017007076642.

Wilson, W.J. (1987). The truly disadvantaged: The inner city, the underclass, and public policy. Chicago: University of Chicago Press.

Winkler, A.E., McBride, T.D., and Andrews, C. (2005). Wives who outearn their husbands: A transitory or persistent phenomenon for couples? Demography 42(3): 523-535. doi:10.1353/dem.2005.0028.

Wooden, M. and Hahn, M. (2014). Female breadwinner families. Families, Incomes and Jobs 9(57): 57-60. 
Vitali \& Arpino: The influence of context on partners' contributions to the household income

\section{Appendix}

Table A-1: Percentage distribution of couple types by country

\begin{tabular}{|c|c|c|c|c|}
\hline & $\begin{array}{l}\text { Male } \\
\text { Breadwinner }\end{array}$ & $\begin{array}{l}\text { Equal } \\
\text { Income }\end{array}$ & $\begin{array}{l}\text { Female } \\
\text { Breadwinner }\end{array}$ & $N$ \\
\hline Cyprus & $61.57 \%$ & $16.08 \%$ & $22.35 \%$ & 547 \\
\hline Bulgaria & $60.42 \%$ & $18.43 \%$ & $21.15 \%$ & 305 \\
\hline Slovenia & $39.02 \%$ & $41.64 \%$ & $19.34 \%$ & 485 \\
\hline Israel & $61.02 \%$ & $20.62 \%$ & $18.36 \%$ & 642 \\
\hline Poland & $63.64 \%$ & $19.26 \%$ & $17.10 \%$ & 425 \\
\hline Estonia & $61.99 \%$ & $21.27 \%$ & $16.74 \%$ & 442 \\
\hline Ireland & $62.90 \%$ & $21.02 \%$ & $16.08 \%$ & 375 \\
\hline Greece & $67.22 \%$ & $17.16 \%$ & $15.62 \%$ & 406 \\
\hline Hungary & $60.79 \%$ & $23.74 \%$ & $15.46 \%$ & 437 \\
\hline Croatia & $57.43 \%$ & $28.38 \%$ & $14.19 \%$ & 461 \\
\hline UK & $70.05 \%$ & $16.43 \%$ & $13.53 \%$ & 549 \\
\hline Russia & $68.24 \%$ & $18.38 \%$ & $13.38 \%$ & 495 \\
\hline Denmark & $57.64 \%$ & $29.06 \%$ & $13.30 \%$ & 446 \\
\hline Sweden & $55.73 \%$ & $32.00 \%$ & $12.27 \%$ & 620 \\
\hline Portugal & $62.39 \%$ & $25.36 \%$ & $12.25 \%$ & 786 \\
\hline Spain & $66.34 \%$ & $21.58 \%$ & $12.09 \%$ & 402 \\
\hline Slovakia & $60.69 \%$ & $27.24 \%$ & $12.08 \%$ & 463 \\
\hline Ukraine & $67.80 \%$ & $20.19 \%$ & $12.01 \%$ & 437 \\
\hline Norway & $60.76 \%$ & $27.47 \%$ & $11.77 \%$ & 426 \\
\hline France & $53.79 \%$ & $35.17 \%$ & $11.04 \%$ & 372 \\
\hline Czech Republic & $77.47 \%$ & $12.34 \%$ & $10.19 \%$ & 473 \\
\hline Belgium & $58.56 \%$ & $31.75 \%$ & $9.69 \%$ & 324 \\
\hline Netherlands & $77.77 \%$ & $12.79 \%$ & $9.44 \%$ & 625 \\
\hline Germany & $75.59 \%$ & $15.26 \%$ & $9.15 \%$ & 562 \\
\hline Finland & $60.48 \%$ & $30.45 \%$ & $9.07 \%$ & 754 \\
\hline Switzerland & $76.20 \%$ & $14.87 \%$ & $8.92 \%$ & 563 \\
\hline Total & $66.74 \%$ & $20.74 \%$ & $12.51 \%$ & 12,822 \\
\hline
\end{tabular}

Note: Countries are in descending order according to the percentage of female-breadwinner couples. 